\title{
Botswana: A Note on Economic Diversification
}

\author{
Lesego Sekwati ${ }^{28}$
}

\begin{abstract}
Despite a series of supportive policies over the years, economic diversification remains an obscurity for Botswana. The economy remains heavily dependent on diamond mining, while the private sector, considered pivotal in the strategy for diversification, continues to be shallow and narrow, with weak inter sectoral diversity and production links. In addition to proliferation of fragmented, uncoordinated policies and/or strategies, which have seriously undermined implementation and monitoring (and accountability in the case of institutions), the paper identifies passive political commitment, especially with regard to supporting innovation, research and development as some of the major contributing factors to sluggish progress on economic diversification. Government's slow rate of response towards addressing factors that inhibit private sector growth and competitiveness (including utility costs, cost of capital, access to land etc) in yester years has also compounded the problem. With renewed vigor and excitement in government in recent times, especially with regard to the "Excellence Strategy" and the "Economic Diversification Drive", it is imperative that these factors be taken on board, otherwise these latest initiatives will only perpetuate what has been the case over the years.
\end{abstract}

Keywords: Economic Diversification, Implementation, monitoring and accountability, Political commitment

\subsection{Introduction}

International experience has shown that diversification is a challenging task, and structural changes are usually slow to implement. For countries which are resource dependent, such as Botswana, the challenges are compounded by the fact that the dominant resource sector is poorly linked with the rest of the economy. It is recognized in the literature however, that a successful diversification plan requires firm political commitment, consistent public policies and substantial financial resources. Notwithstanding implementation of a succession of policies for economic diversification over the years, the economy of Botswana remains heavily dependent on the diamond mining sector (see Figures 1 through 3 below which show sectoral distribution of GDP overtime). According to Zizhou (2009), Botswana had one of the highest Export Concentration Index (ECI) in Africa, second highest in SADC after Angola in 2006, reflecting the high dependence on diamond revenues. The private sector continues to be narrow and shallow, characterized by weak inter sectoral diversity and production links, and high dependency on public expenditure. The critical question that comes to the fore then is, why is this case? Why have both horizontal and vertical policies implemented over the years had little impact on diversification? Is it a question of misdirected policies and incentives? Is it a case of weak institutional framework to support implementation and monitoring? Or is it a case of weak political commitment? This brief discussion highlights some of these critical issues. For Botswana, and other resource dependent economies, diversification is of fundamental importance given the experience resulting from the recent global economic downturn which provided evidence that such economies remain highly vulnerable to external shocks arising from commodity price fluctuations. For Botswana, real GDP declined by 4.6\% during 2009 owing to the decline in real value added by the mining industry (Republic of Botswana 2010). The diamond mining sector itself recorded a decline of $31.4 \%$ during the same period. Official statistics also show that mineral revenues collected during the 2008/2009 financial year were $32 \%$ lower compared to 2007/2008 receipts.

\footnotetext{
${ }^{28}$ Lecturer, Department of Economics, University of Botswana. Email: Sekwatil@mopipi.ub.bw
} 
Figure 1: Sectoral Distribution of GDP in 2009 - (percentages)

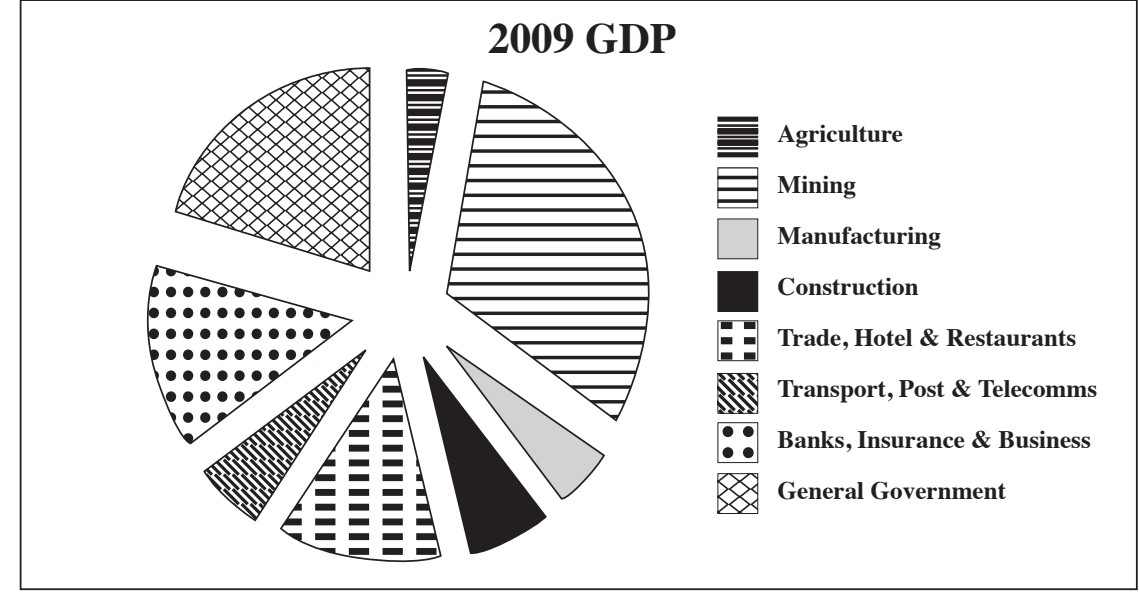

Source: Bank of Botswana (2010)

Figure 2: Sectoral Distribution of GDP in 1985/86 - (percentages)

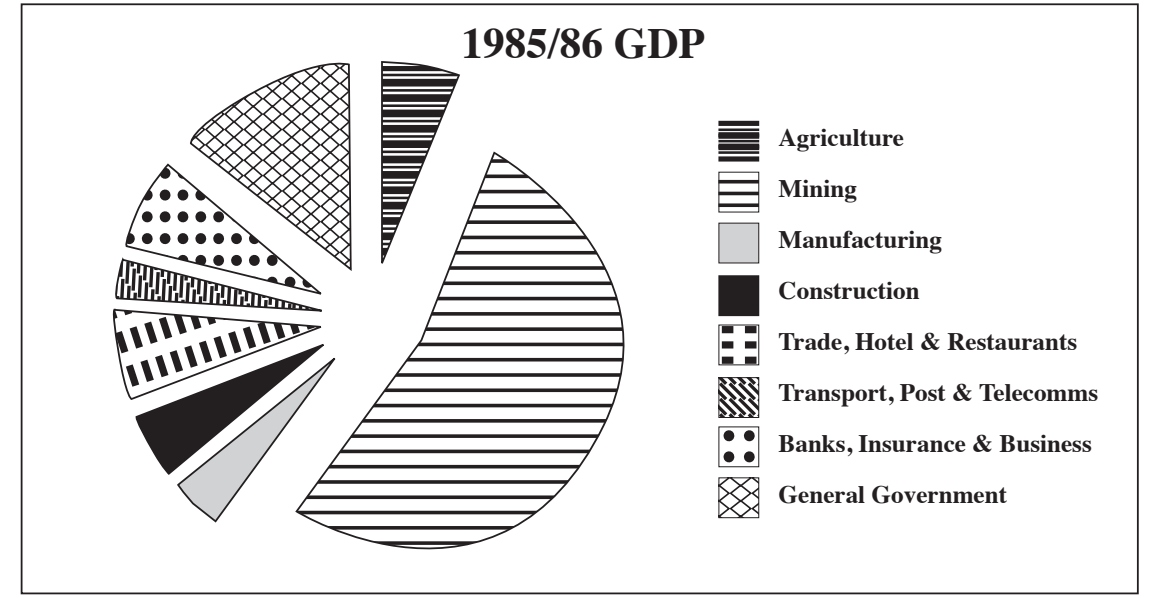

Source: Siphambe et al (2005)

Figure 3: Sectoral Distribution of GDP in 1975/76 - (percentages)

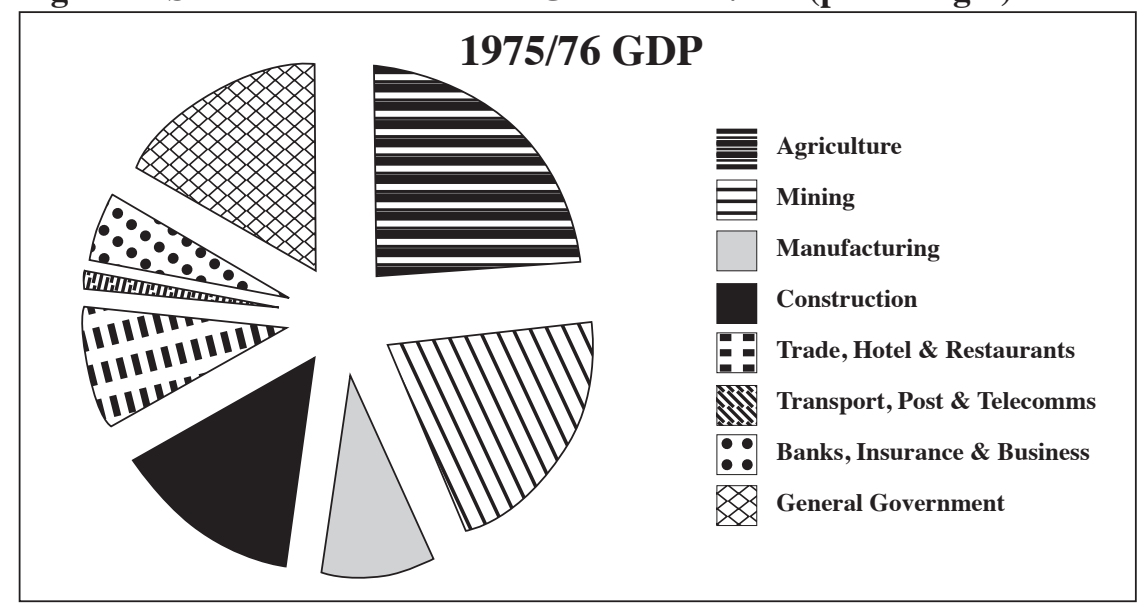

Source: Siphambe et al (2005) 


\subsection{Botswana Strategy for Diversification}

Economic diversification efforts in several countries have placed emphasis on promoting industrialization. This is premised on the belief that industrialization provides greater potential for long term growth compared to resource based economies. Botswana has as well recognized the potential of industrialization in achieving the same. Efforts to promote industrialization in Botswana can be traced through the various national development plans, including the Industrial Development Act of 1968. The Act provided the basis for the subsequent policies on industrial development. The fundamental purpose of the policies is to develop the private sector through targeted entrepreneurial development incentives and support mechanisms. It is in this context that private sector development has been synonymous with economic diversification in Botswana. The 1984 Industrial Development Policy (IDP), based on the import substitution strategy, provided the initial impetus for industrial development in Botswana. The strategy involved producing for the domestic market and substituting for imports. It also became the underlying premise of Botswana's industrial policy and subsequent national development plans. Owing to growing international competition spurred by globalization, Botswana has had to revise this policy stance during the 1990s. First, there was the expected reduction in trade barriers following a number of trade negotiations, including the WTO agreement which had important implications for SACU. The SADC Protocol on Trade Cooperation signed in 1996 compounded the challenges. The rapid introduction of more productive technology as well as improved business operation procedures also added to the increasing competition (Republic of Botswana 1998a). These new competitive pressures provided impetus for a shift in policy focus. In response to these challenges, government adopted a new industrial development policy in 1998, based on encouraging highly productive and efficient export based industries.

Promotion and expansion of efficient supporting services and component manufacturers were identified as key in this strategy. In addition to large scale enterprises, the policy recognized SMMEs as important drivers of industrialization. One crucial element of the industrial policy thus involved addressing directly the challenges faced by SMMEs. This resulted in the 1998 policy on SMMEs. The fundamental goal of the policy is to encourage the development of a competitive and sustainable SMME sector while promoting vertical integrations and horizontal linkages between the primary industries and SMMEs (Republic of Botswana 1998b). Prior to the establishment of the Citizen Entrepreneurial Development Agency (CEDA) in 2001, the Financial Assistance Policy (FAP) was one of the most significant initiatives for supporting enterprise development. Introduced in 1982, FAP consisted of a capital grant to assist the start up or expansion of manufacturing, agriculture and tourism projects. Following the recommendations of its fourth evaluation report, FAP has since ceased to exist amid instances of abuse, overinvestment in rarely used machinery, and poor monitoring as well. Unlike the FAP, CEDA provides loans to citizen owned enterprises at subsidized interest rates as opposed to outright grants as under the FAP. Managed by Venture Partners Botswana, CEDA also has a P200 million venture capital fund used to finance citizen owned companies or joint ventures with foreign investors. The fund provides risk capital by way of equity and/or quasi equity and other debt instruments. The fund invests in Greenfield and early stage projects; established companies needing capital to expand; mergers and acquisitions; turnarounds as well as management buy-outs and buy-ins, to facilitate transfer of ownership to existing or new shareholders. Established under the Small Business Act of 2004, the Local Enterprise Authority (LEA) is another key agency, expected to play a critical role in promoting entrepreneurship and enterprise development among the SMME community in Botswana. It plays a leading role in the implementation of the SMME policy.

One critical area, acknowledged as well by the industrial development policy is the need to increase productivity in both private and public institutions. The key institution in this regard is the Botswana National Productivity Centre (BNPC), established to promote productivity improvement in all sectors of the economy. Poor work ethic and lack of appropriate skills have been identified as some of the major reasons resulting in low productivity in most enterprises in 
Botswana. Other incentives aimed at supporting SMMEs include the Local Preference Scheme (1976), replaced by the Local Procurement Programme in 1997, Reserved Sectors Policy (1982), and the Selibe Phikwe Regional Development Programme (1988). The objective of the Local Preference Scheme was to give local producers preference in the supply of goods and services to government. The Local Procurement Programme reserves 35\% of government purchases to local producers. Beneficiaries must be licensed and satisfy any two of the following conditions: employ not more than 200 persons; have an annual turnover of between P200, 000 and P5 million; and have an investment in productive machinery of between P50, 000 and P5 million (Republic of Botswana 1998a). Phased out in 1996, the objective of the Selibe Phikwe Regional Development Programme was to stimulate economic development in the area around Selibe Phikwe, where copper-nickel mining is the main economic activity. The Selibe Phikwe Economic Diversification Unit, a joint project between the government of Botswana and the European Union, was recently established in an effort to diversify the activities of the mining town, and the surrounding areas. The Reservation Policy (1982) continues to exist though it has been revised over the years. The policy is meant to promote citizen participation in the economy by reserving certain economic activities for them only. In recent times, joint ventures between citizens and foreign investors have been allowed to benefit from the scheme (Zizhou 2009).

Although the pace of privatization has been sluggish, the industrial development policy acknowledges the importance of privatization in promoting industrialization and private sector growth. With plans to privatize the national airline (Air Botswana) falling through during 2008, plans are at an advanced stage to privatize the Botswana Telecommunications Corporation (BTC) during the first half of 2011. The work to develop a privatization strategy for the National Development Bank $\left(\mathrm{NDB}^{29}\right.$ ) has also been completed and government is considering the proposed strategy and the associated divestiture action plan (Republic of Botswana 2010). Following the approval of the privatization policy (2001), government established the Public Enterprises Evaluation and Privatization Agency (PEEPA) to spearhead privatization of public enterprises in Botswana. Pursuant to the policy, the privatization master action plan was approved in 2005. One of the main strategies envisaged to promote private sector participation under the master plan is promoting Public Private Partnerships (PPPs). PEEPA is in the process of developing the overall guiding policy and setting up an effective regulatory framework for PPPs.

The 1998 Industrial Development Policy as well recognizes the importance of tourism and agriculture in promoting industrial development. Government is currently reviewing the 1990 Tourism policy in an effort to address the challenges faced by the tourism industry. Limited product diversity remains one of the key challenges facing the industry. The review is also expected to address limited citizen participation in the sector. With regards to agriculture, government has in recent years adopted NAMPAAD ${ }^{30}$ and ISPAAD ${ }^{31}$ with a view to commercializing the sector and increasing agricultural output. It should be noted that at independence, agriculture was the main economic activity, accounting for about $42.7 \%$ of GDP in 1966. Subsequent to the discovery of minerals during the 1970s, its contribution has been declining since. Over the last decade, the contribution of the sector has averaged less than 3\% (see Table 1 below). The idea behind the recent policy initiatives is to reverse this trend.

In addition to these initiatives, government established some key institutions to drive economic diversification. Important among these are the Botswana Development Corporation

\footnotetext{
${ }^{29}$ NDB was established in 1963 as a development finance institution with special emphasis on financing the agricultural sector. The agricultural sector remained in primary focus for the first 20 years, but has since expanded its portfolio following a restructuring exercise in 1994.

${ }^{30}$ National Master Plan for Arable Agriculture and Dairy Development. Introduced in 2002 to increase agricultural productivity by promoting irrigated agriculture, dairy development, providing insurance cover for farmers as well as infrastructure development.

${ }^{31}$ Integrated Support for Arable Agricultural Development. Introduced in 2009 to increase grain production as well as commercialize agriculture. Key policy actions include facilitation of access to credit and cluster fencing.
} 
(BDC), the Botswana Export Development and Investment Authority (BEDIA) and recently the International Financial Services Centre (IFSC). Established in 1970, BDC is a development finance institution, created to fund commercially viable businesses and projects for the development and diversification of the economy. The Corporation also assists start ups whose risks are high, but are considered to have strategic development potential (Republic of Botswana 2005). The Corporation invests in medium to large scale enterprises through equity participation, loan financing, guarantees and the development of business premises for lease or hire. BDC's portfolio covers manufacturing, agribusiness, services, as well as property development and management. Projects currently under implementation include a glass manufacturing plant, with an estimated cost of P500 million; manufacturing and supply of steel pipes estimated at over P130 million (Republic of Botswana 2010). BEDIA was established in 1997, with the objective of promoting the establishment of manufacturing enterprises. It also identifies market outlets for goods manufactured in Botswana, and provides a service facility for potential investors to expedite clearances, residence and work permits, and factory space as well as land allocation. Established in 2003, the IFSC aims to establish and develop Botswana as a hub for cross border financial and business services in to Africa and the region. Following government's rationalization of public enterprises, IFSC is to be merged with BEDIA, under the Ministry of Trade and Industry. The restructuring process is ongoing.

Table 1: Changes in the structure of the Economy (Selected Years) $\square$ in percent of GDP

\begin{tabular}{|l|c|c|c|c|c|c|}
\hline & $\mathbf{1 9 6 6}$ & $\mathbf{1 9 7 5} / \mathbf{7 6}$ & $\mathbf{1 9 8 5} / \mathbf{8 6}$ & $\mathbf{1 9 9 5} / \mathbf{9 6}$ & $\mathbf{2 0 0 5}$ & $\mathbf{2 0 0 9}$ \\
\hline Agriculture & 42.7 & 20.7 & 5.6 & 4.1 & 1.8 & 3.0 \\
\hline Mining & - & 17.5 & 48.9 & 33.9 & 38.0 & 26.0 \\
\hline Manufacturing & 5.7 & 7.6 & 3.9 & 4.8 & 3.5 & 4.0 \\
\hline Water\&Electricity & 0.6 & 2.3 & 2.0 & 2.1 & 2.4 & 2.9 \\
\hline Construction & 7.8 & 12.8 & 4.6 & 6.2 & 4.4 & 5.2 \\
\hline $\begin{array}{l}\text { Trade, } \\
\text { Hotels\&Restaurants }\end{array}$ & 9.0 & 8.6 & 6.3 & 9.9 & 10.3 & 13.6 \\
\hline $\begin{array}{l}\text { Transport, } \\
\text { post\&Telecomms. }\end{array}$ & 4.3 & 1.1 & 2.5 & 3.6 & 3.6 & 4.9 \\
\hline $\begin{array}{l}\text { Banks, } \\
\text { Insurance\&Business }\end{array}$ & 20.1 & 4.7 & 6.4 & 11.2 & 10.5 & 12.4 \\
\hline General Government & 9.8 & 14.6 & 12.8 & 15.4 & 17.0 & 18.5 \\
\hline
\end{tabular}

Source: Siphambe et al (2005), Bank of Botswana (2010)

\subsection{Challenges for Economic Diversification}

Notwithstanding the spate of policies, strategies and incentive schemes implemented by government to promote economic diversification over the years, the economy of Botswana remains heavily dependent on diamond mining, with a narrow and shallow private sector. The situation continues to be a "mind boggler" or "paradox" for policy researchers and makers alike. Questions continue to be asked why initiatives undertaken are not having the desired effect. Were the policies and/or incentives misdirected? Is Botswana a victim of its own making through proliferation of policies and strategies and/or institutions that make implementation difficult? Was political commitment enough to push the agenda? As acknowledged in the literature, without political commitment, any economic diversification efforts are doomed to fail. Political commitment in this regard is viewed in the context of providing an enabling 
environment or a supporting framework for the policies adopted to have any meaningful impact. For a very long time research on factors that inhibit growth of the private sector (including high utility costs, business registration and licensing, work and residence permits, access to land etc) have been conducted, the recommendations for which are yet to be implemented. Although government has in certain instances been compared to a large ship navigating very slowly through the sea, it takes firm commitment on the part of government to respond in a reasonable amount of time to the challenges that threaten to derail the ship. Provision of policy guidance is necessary but insufficient; government has to be seen to be responding to private sector needs if any inroads are to be made with regards to diversification. How much is government committed to research and development? Countries that have been successful in diversifying their economies have channeled a sizable amount of resources to research and development to support the growth of industry. Is this happening in Botswana? It is not a question of establishing new institutions to undertake research. Government only has to use existing institutions such as the University of Botswana and the envisaged University of Science and Technology, Botswana Technology Centre, Botswana Institute for Development Policy Analysis more effectively by providing funds for industry relevant research. Equally important is a competitive labour force. It has become increasingly evident over the years that there is a mismatch between the skills required by the industry, and the graduates produced by tertiary institutions in Botswana. While it is important for the institutions to continually review themselves to ensure that they remain relevant, it is equally significant for government to ensure that training funds are channeled to where it is necessary. The Human Resource Development Strategy will hopefully be responsive to some of these challenges.

It is a fact that Botswana has adopted a plethora of policies, strategies and programmes to diversify the economy. It is also a fact that most of these policies have been piece meal, fragmented and uncoordinated. This has certainly contributed to implementation and monitoring problems in a number of implementing agencies, including government departments. Implementation and monitoring have also not been helped by the fact that most of these policies, strategies and/or programmes lack clearly defined performance indicators and monitoring mechanisms, let alone time frames within which specific policy actions are to be implemented. The proliferation of institutions supposed to drive diversification has also compounded the problem. For a long time, there has been serious duplication of effort, and uncoordinated operations among these institutions, sometimes resulting in rivalries, undermining the very objectives that they were established for. It is hoped however that some of these problems will be addressed through the rationalization of public enterprises. The objective of the rationalization process is to merge public enterprises with similar mandates, to reduce duplication and improve efficiency of implementation. To this end, several public enterprises are in line to be merged, while others are signing memoranda of agreement to work together.

\subsection{Renewed Impetus towards Economic Diversification}

In recent times, there seems to be renewed excitement and vigour on the part of government with regards to economic diversification. In consultation with the private sector, quasi government institutions and other relevant stakeholders, government is in the process of developing an economic diversification master action plan. The master action plan is meant to facilitate the implementation of the economic diversification drive (EDD) initiative. The short term strategy of the EDD initiative is to use administrative interventions to use local procurement, and government preference margins to promote the development of local companies. The long term strategy is to develop a vibrant and globally competitive private sector, independent of government support and protection. The master action plan, which is developed using the balanced scorecard approach to enhance performance monitoring and evaluation, has six notable thematic areas. These are: Sectoral Development and Linkages; Investment and Finance; Research, Innovation, Technology Development and Transfer; Export Development and Promotion; Entrepreneurship Development; as well as Quality Control, Standards and 
Production. Furthermore, in line with the Botswana Excellence Strategy (2008), government has set up a National Strategy Office under the Office of the President, to coordinate implementation of economic diversification initiatives. It is imperative however that significant change with regard to issues discussed above be made, otherwise economic diversification will remain elusive for Botswana.

\section{References}

Bank of Botswana (2010), Botswana Financial Statistics, Bank of Botswana, Gaborone, Botswana

Republic of Botswana (1998a), Industrial Development Policy, Ministry of Commerce and Industry, Gaborone, Botswana

Republic of Botswana (1998b), Policy on Small, Medium and Micro Enterprises, Ministry of Commerce and Industry, Gaborone, Botswana

Republic of Botswana (2005), Privatization Master Plan, Ministry of Finance and Development Planning, Gaborone, Botswana

Republic of Botswana (2008), Botswana Excellence - A Strategy for Economic Diversification and Sustainable Growth, Office of the President, Gaborone, Botswana

Republic of Botswana (2010), Budget Speech, Ministry of Finance and Development Planning, Gaborone, Botswana

Siphambe H.K., Narayana N., Akinkugbe O., and Sentsho J (2005), Economic Development of Botswana: Facets, Policies, Problems and Prospects, Bay Publishing, Gaborone, Botswana

Zizhou F (2009), Linkages between Trade and Industrial Policies in Botswana, Southern African Development Research Network 